\title{
Hard Capsule Dosage Form
}

National Cancer Institute

\section{Source}

National Cancer Institute. Hard Capsule Dosage Form. NCI Thesaurus. Code C64904.

A capsule covered with a rigid outer shell. 